Supplement of Atmos. Chem. Phys., 15, 3429-3443, 2015

http://www.atmos-chem-phys.net/15/3429/2015/

doi:10.5194/acp-15-3429-2015-supplement

(C) Author(s) 2015. CC Attribution 3.0 License.

(c) (i)

Atmospheric

Chemistry

and Physics

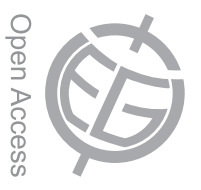

Supplement of

\title{
Total sulfate vs. sulfuric acid monomer concenterations in nucleation studies
}

\author{
K. Neitola et al.
}

Correspondence to: K. Neitola (kimmo.neitola@fmi.fi) 


\section{Supplementary material}

\section{Losses of sulphuric acid to particles}

Losses of sulphuric acid to the particle phase were calculated using the DMPS-measured number size distribution at the end of the flow tube. The total volume of the number size distribution was calculated and the particles were assumed to be composed of pure sulphuric acid. The assumption is the upper limit, as sulphuric acid is very hygroscopic and draws water from the humidified carrier gas and the contaminants from the carrier gas condense on the particles too. On the other hand, at the highest saturator temperature, the size distribution of the particles extends beyond the measurement range of the DMPS (3-250 $\mathrm{nm}$ ) which causes an underestimation of the losses of sulphuric acid to particles. This was the case when the temperature of the saturator was above $300 \mathrm{~K}$.

Figure S1 presents the calculated losses of sulphuric acid to the particles (open stars) calculated from two independent measurement sets as a function of saturator temperature for MARGA and CIMS measurements at RH of $30 \%$. Also, gas phase monomer concentration measured by CIMS (red-filled circles), the sum of gas-phase monomer and losses to the particles (red triangles), total-sulphate concentration measured by MARGA (blue triangles) and predicted sulphuric-acid concentration by Eq. (1) (black solid line) are presented. The losses to the particle phase agree well between the two datasets (MARGA and CIMS) and overlap when the datasets have the same saturator temperatures. The sum of gas-phase monomer and the losses to the particle phase is one-to-two orders-of-magnitude lower than the prediction by Eq. (1) or the measured total sulphate measured with MARGA. The sulphuric acid undetected by mass spectrometers is not in the larger particles, as Fig. S1 shows. We assume it to be hidden in small clusters that are below the detection limit of particle counters and are either unidentified from the mass spectra of CI-Api-TOF, or the sulphuric acid is bound to some base molecules in a configuration which prevents the ionization mechanism to work in the CI-inlet.

\section{The inlet design}

Figure S2 is a schematic of the saturator test's sampling-line arrangement. Outlet of the saturator is a SS-tube (I.D. $4 \mathrm{~mm}$, length $6 \mathrm{~cm}$ ) connected to the mixer part. The mixer part is made of SS-tubes (I.D. $10 \mathrm{~mm}$, length between T-parts is $10 \mathrm{~cm}$ ). The mixing flow enters the mixer by surrounding the flow from saturator. After the outlet of saturator ends, there is turbulent mixing before the flow is divided to the instruments and excess flow. Different configurations were tested (i.e. CIMS with the flow going straight from the mixer, CI-Api-TOF behind the 90 degree angle) but the difference was well within the uncertainty of the instruments.

\section{Effect of different carrier gases on the measured sulphuric-acid concentration}

Separate experiments were done to make sure that the contaminant levels of the carrier gas (pressurized air) is not the cause of the discrepancy between CIMS measured monomer concentration and the total-sulphate concentration. Three different purity carrier gases were used: purified, particlefree pressurized air; nitrogen (5.0) and nitrogen (6.0). The $\mathrm{N}_{2}$ (5.0) was taken from two sources; from a cylinder and from a liquid $\mathrm{N}_{2}$ source. The purity is the same (5.0, i.e. $99.999 \%$ ) but the relative amount of different contaminants might differ. The carrier-gas experiments were conducted with the same setup as presented in Fig. 1 in the main manuscript. 
Two separate purity sulphuric acid samples were used inside the saturator (100\% and $97 \%$ wt.). The $100 \%$ sulphuric acid is so-called fuming sulphuric acid, since it acts as a source of $\mathrm{SO}_{3}$, which might react with water to produce sulphuric acid. This would cause the measured sulphuric acid monomer concentration to be higher with $\mathrm{H}_{2} \mathrm{SO}_{4}$-purity of $100 \%$ than with $97 \%$. As the measurements were conducted in dry conditions (i.e. no added water vapour), the water originates from the carrier gas $\left(\mathrm{N}_{2}(5.0)<3\right.$ ppm, $\left.\mathrm{N}_{2}(6.0)<0.5 \mathrm{ppm}\right)$ and it is expected to react with the $\mathrm{SO}_{3}$ that will produce sulphuric acid inside the saturator.

Sulphuric-acid monomer concentration was measured using CI-Api-TOF. The monomer concentration was averaged over the time each saturator temperature was constant, as defined in the main manuscript. The normalized monomer concentration as a function of saturator temperature for three different carrier gases and two sulphuric-acid purities are presented in Fig. S3. The mixing and saturator flow rates are the same carrier gas. The values are normalized to the maximum value of monomer concentration for each of mixing flowrate. This was done to be able to compare the results from each of the $\mathrm{H}_{2} \mathrm{SO}_{4}$-purity experiments, as the mixing flowrates were different. The flowrate through the saturator was $0.5 \mathrm{lpm}$ throughout the experiment. It is evident from the Fig. S3 that neither the carrier-gas purity, nor the sulphuric-acid purity affects the measured monomer concentration: validating the original assumption of the $\mathrm{SO}_{3}$ conversion already inside the saturator. The monomer concentration increases as a function of saturator temperature exponentially, as expected. The difference between carrier-gas purity $\left(\mathrm{N}_{2} 5.0\right.$ and 6.0) and between carrier gases (pressurized air and $\mathrm{N}_{2}$ ) are small and well within the uncertainty of CI-Api-TOF (factor of two). Due to the fast inlet flowrate of the CI-Api-TOF (10 lpm) only three points were measured for $\mathrm{N}_{2}(6.0)$, as the bottled gas was consumed very fast. The datasets in Fig. S3 clearly demonstrate that the purity of the pressurized air does not affect the measured monomer values.

\section{Saturator flowrate tests}

A saturator flowrate test was done using different carrier gases. The CI-Api-TOF measured sulphuricacid monomer concentrations as a function of the saturator flowrate was compared to the predictions by Eq. (1) (black, solid line with $T_{\text {sat }}=283 \mathrm{~K}$ and grey, starred line with $T_{\text {sat }}=293 \mathrm{~K}$ ) using different carrier gases (blue, red and black squares for pressurized air, $\mathrm{N}_{2} 5.0$ and 6.0, respectively) at two different saturator temperatures (Fig. S4). The mixing flowrates were slightly different for the two temperatures (15.2 and $15.3 \mathrm{lpm}$ for $T_{\text {sat }}=283 \mathrm{~K}$ and $T_{s a t}=293 \mathrm{~K}$, respectively). Only nitrogen (6.0, grey stars) was used for saturator temperature 293 K. $100 \%$ sulphuric acid was used in this experiment. The measured monomer concentration was one-to-two orders-of-magnitude lower than the predicted values throughout the saturator flowrate range for both saturator temperatures. No difference between the carrier gases was observed and the measured points coincide at similar saturator temperatures.

Another flowrate experiment was conducted using $97 \%$ sulphuric acid and CI-Api-TOF to investigate if different carrier gases affect the ratio between monomer, dimer and trimer, as it is suggested that the ratio depends on the contaminant concentration (Petäjä et al., 2011; Jen et al., 2014). Measured monomer, dimer and trimer concentrations were compared to each other and to the predicted sulphuric-acid concentration from Eq. (1) using three carrier gases (pressurized air, liquid $\mathrm{N}_{2} 5.0$ and bottled $\mathrm{N}_{2} 6.0$ ) at the saturator temperature of approximately $288 \mathrm{~K}$ (Fig. S5). The points 
in Fig. S5 are colour coded for carrier gases and different shapes present monomer, dimer and trimer concentrations: black is $\mathrm{N}_{2}(6.0)$, red is liquid $\mathrm{N}_{2}$ (5.0) and blue is pressurized air, squares are monomer, triangles are dimer and stars are trimer concentrations. The experiment was started with the most-pure carrier gas and then moving subsequently to the lesser-pure one (i.e. $\mathrm{N}_{2} 6.0$ first, liquid $\mathrm{N}_{2} 5.0$ second and pressurized air third) to make sure that impurities from other carrier gases would not affect the measurements. Due to this order, the measured sulphuric acid concentration at the slowest two flow rates with $\mathrm{N}_{2}$ (6.0) are lower than with the other carrier gases, as the measurement setup and lines were cleaned before the experiment and the walls were not yet saturated with sulphuric acid. The y-axis is limited to $5 \cdot 10^{4} \mathrm{~cm}^{-3}$, which is considered the lower detection limit of the CI-ApiTOF. The ratios of measured monomer to dimer, monomer to trimer or dimer to trimer concentration remain constant throughout the saturator flowrate range with all carrier gases and are constant even when comparing between carrier gases. This result clearly supports our conclusion that the discrepancy between the sulphuric-acid concentrations measured with mass spectrometers and the total sulphate measured with MARGA is not dependent on the carrier gas.

\section{The influence of mixing flowrate}

The influence of the mixing flowrate was tested using $\mathrm{N}_{2}$ (6.0). The mixing flow rate $Q_{\text {mix }}$ was changed from $10 \mathrm{lpm}$ to $16.8 \mathrm{lpm}$ and the sulphuric-acid monomer was measured using the CI-ApiTOF and compared to the prediction from Eq. (1) at the saturator temperature of $283 \mathrm{~K}$. The saturator flowrate was $0.5 \mathrm{lpm}$. The ratio of maximum and minimum measured value was 1.73 , compared to the ratio of the mixing flowrates of 1.68 shows that the only influence of the mixing flow rate is dilution, as expected.

\section{Mass spectra from $\mathrm{Cl}-\mathrm{Api}$-TOF and correlation to $\mathrm{H}_{2} \mathrm{SO}_{4}$ monomer concentration}

The measurements with different carrier gases as a function of saturator temperature were further investigated to discover where the sulphuric acid was "hidden". Each saturator temperature (278 K, $288 \mathrm{~K}, 298 \mathrm{~K}$ and $308 \mathrm{~K}$ ) for the three carrier gases (pressurized air, liquid $\mathrm{N}_{2}, 5.0$ and $\mathrm{N}_{2}, 6.0$ ) were separated and the signals in the mass spectra of CI-Api-TOF were averaged over the time when the system was in steady state (i.e. measured monomer concentration was constant). The signals were averaged to nearest unit mass-to-charge (i.e. stick masses). The signals below $500 \mathrm{Th}$ mass-to-charge $(\mathrm{m} / \mathrm{Q})$ were then correlated to $97 \mathrm{Th}\left(\mathrm{HSO}_{4}{ }^{-}\right)$, which is signal from sulphuric-acid monomer alone (Fig. S6-S8). In Fig. S6-S8, the panel a) is the coldest saturator temperature $278 \mathrm{~K}$, panel b) $288 \mathrm{~K}$, panel c) $298 \mathrm{~K}$ and panel d) $308 \mathrm{~K}$. The bottled nitrogen (6.0) ran out before the highest saturator temperature, so there are only three panels in Fig. S8. The number of correlating (and anti-correlating) peaks increases as a function of the increasing saturator temperature with all three carrier gases and the number of these peaks are similar with all carrier gases in similar temperatures. The correlating peaks $(\mathrm{m} / \mathrm{Q})$-position differ between carrier gases suggesting different contaminants in the carrier gases. Figures S6-S8 show that the sulphuric acid is distributed to a wide range of cluster configurations, which are not used in calculating the monomer, dimer or trimer concentrations. Unfortunately calculating the actual concentration of the sulphuric acid in these clusters is impossible as their charging efficiency (i.e. calibration constant) and their chemical composition are unknown. This prevents summing the total sulphuric acid concentration even from the peaks that are correlating with 97 Th. The peaks in Fig. S6-S8 are only those below 500 Th and showing relatively large (anti- 
) correlation with the $\mathrm{HSO}_{4}{ }^{-}$, but even identifying each of these peaks is a large task and it is not in the scope of this work. The actual mass spectrum of CI-Api-TOF contains an even-larger amount of signal peaks, as not all of the peaks (anti-) correlate with peak 97 Th. This is illustrated in Fig. S9S11, where one-hour-average spectra are presented first in a (m/Q)-range from 25 to $500 \mathrm{Th}(\mathrm{S} 9)$ and then zoomed to range 300-500 Th (S10) and 400-500 Th (S11). $\mathrm{N}_{2}$ (6.0) was used as carrier gas and the saturator temperature was $298 \mathrm{~K}$. In Fig. S9, the peaks used for calculating the monomer, dimer and trimer concentration are named. When zooming to smaller mass-to-charge range, more-and-more peaks appear in the spectrum. Here one must consider that in Fig. S9 data are only presented for (m/Q)-ratio range from 25 to $500 \mathrm{Th}$ but there are more, larger clusters beyond $500 \mathrm{Th}$, together with the fact that CI-inlet uses a selective charging mechanism; excluding a large portion of possible cluster configurations from charging and hence, from detection.

\section{Modelled growth rates}

The model from Škrabalová et al. (2014) was used to calculate the resulting diameter $\left(D_{p}\right)$ and growth rate $(G R)$ of the particles using the measured sulphuric-acid monomer and total-sulphate concentrations (presented in Fig. 6 and 7, panel d)). The used conditions were RH of $30 \%$, temperature of $298 \mathrm{~K}$ and residence time $\tau$ of $30 \mathrm{~s}$. The measured sulphuric-acid monomer and totalsulphate concentrations were converted to the initial values (i.e. at the beginning of the flow tube) by using the determined TLFs (14.2 and 10.0 for CIMS and MARGA, respectively) for input parameter for the model. Initial size of the clusters was chosen to be $1.5 \mathrm{~nm}$ (Kulmala et al., 2007). Three different ammonia uptake scenarios were used: (0) no uptake of ammonia, particles composed of sulphuric acid and water, (1) uptake of ammonia at the same rate as sulphuric acid, resulting in ammonium bisulphate-water particles and (2) double uptake rate of ammonia compared to sulphuric acid forming ammonium sulphate-water particles. With the initial sulphuric-acid monomer as an input parameter, the growth rates ranged approximately from 1 to $15 \mathrm{~nm} \mathrm{~h}^{-1}$ as a function of sulphuric-acid concentration (i.e. saturator temperature $T_{s a t}$ ). With these growth rates, the resulting diameters were below $2 \mathrm{~nm}$, which are drastically smaller than the observed mean diameters (Fig. S12, left panel). When using initial total-sulphate as an input, the growth rates were much larger, ranging from 1250 to $2300 \mathrm{~nm} \mathrm{~h}^{-1}$, depending on the scenarios used and the total-sulphate available. Using these growth rates, the resulting particle diameters were similar as the observed mean diameters (Fig. S12, right panel). Taking sulphate into account increases growth rates dramatically, compared to growth rates by sulphuric-acid monomer measured with mass spectrometers.

\section{References}

Jen, C. N., P. H. McMurry and D. R. Hanson: Stabilization of Sulfuric Acid Dimers by Ammonia, Methylamine, Dimethylamine, and Trimethylamine, J. of Geophys. Res. Atmos., accepted, 2014.

Kulmala, M., Riipinen, I., Sipilä, M., Manninen, H. E., Petäjä, T., Junninen, H., Dal Maso, M., Mordas, G., Mirme, A., Vana, M., Hirsikko, A., Laakso, L., Harrison, R. M., Hanson, I., Leung, C., Lehtinen, K. E. J., Kerminen, V.-M.: Towards direct measurement of atmospheric nucleation, Science, 318, 89, DOI: 10.1126/science.1144124, 2007. 
Petäjä, T., M. Sipilä, P. Paasonen, T. Nieminen, T. Kurtén, I. K. Ortega, F. Stratmann, H. Vehkamäki, T. Berndt and M. Kulmala: Experimental Observation of Strongly Bound Dimers of Sulfuric Acid: Application to Nucleation in the Atmosphere, Phys. Rev. Lett., 106: 228302, 2011.

Škrabalová L., Brus, D., Anttila, T., Ždímal, V. and Lihavainen H.: Growth of sulphuric acid nanoparticles under wet and dry conditions, Atmos. Chem. Phys. 14, 6461-6475, doi:10.5194/acp14-6461-2014, 2014.

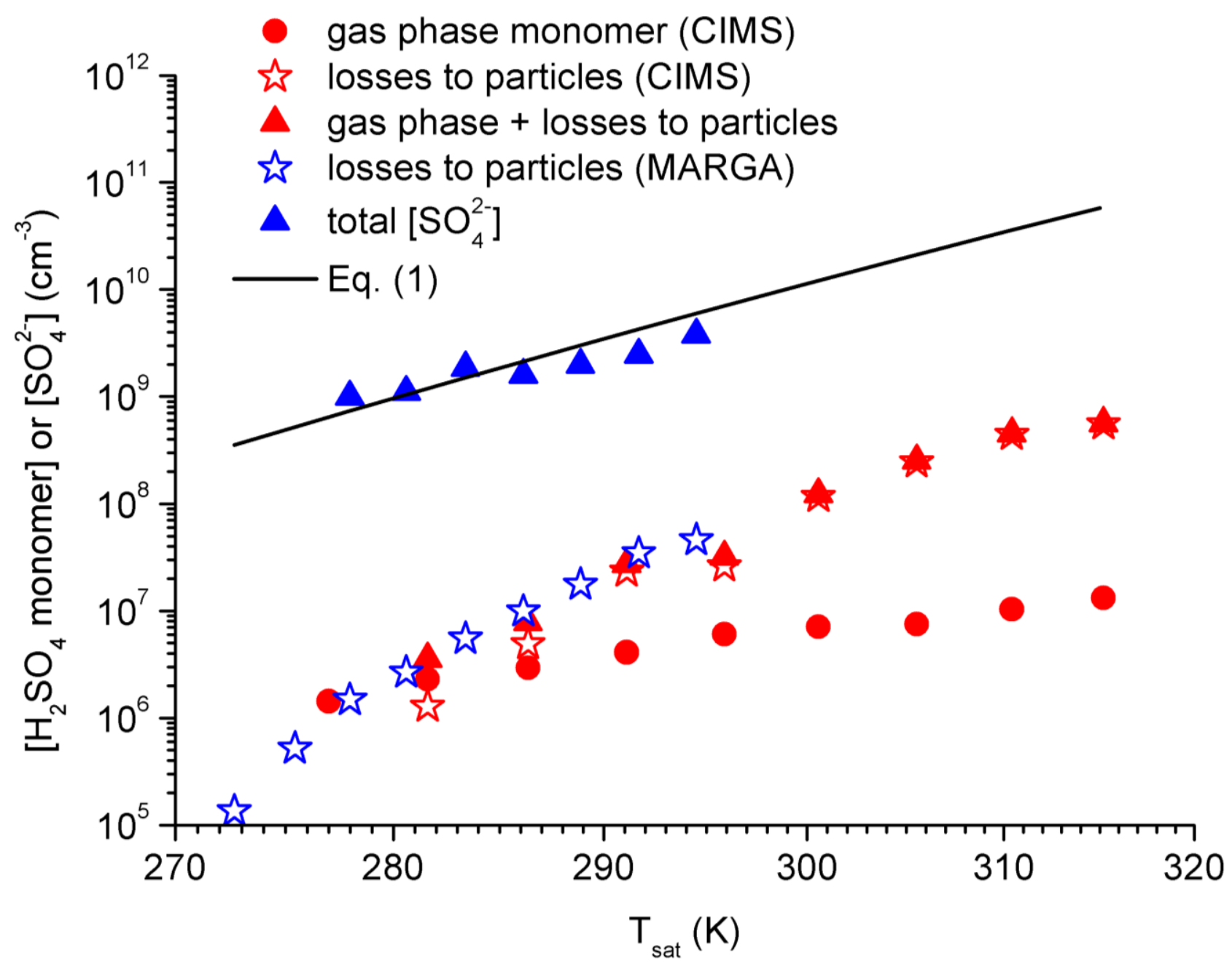

Figure S1. Calculated losses of sulphuric acid to the particles as a function of saturator temperature from two independent datasets for CIMS (open red stars) and MARGA (open blue stars) at RH of 30 $\%$ measured at the end of the flow chamber. Presented are also gas-phase monomer concentration measured with CIMS (filled red circles), sum of gas-phase monomer and losses to the particles (red triangles), total sulphate measured with MARGA (blue triangles) and predicted sulphuric-acid concentration by Eq. (1) (black solid line), all as a function of saturator temperature. 


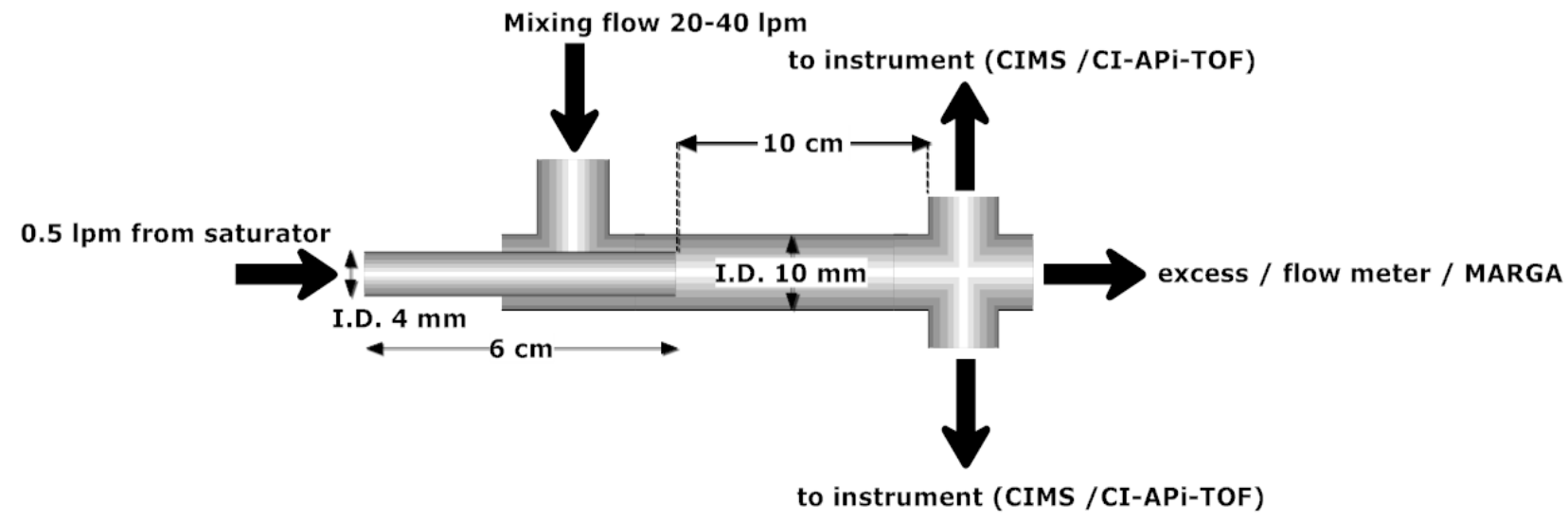

Figure S2. Inlet design for saturator tests. $0.5 \mathrm{lpm}$ flow from the saturator is brought through a SStube (I.D. $4 \mathrm{~mm}$, length $6 \mathrm{~cm}$ ). Mixing flow (20-40 lpm) comes through an SS-tube (I.D. $10 \mathrm{~mm}$ ). The I.D. $4 \mathrm{~mm}$ SS-tube ends $2 \mathrm{~cm}$ after the mixing flow T-part so that the mixing flow enters as sheath flow surrounding the I.D. $4 \mathrm{~mm}$ pipe (co-flow configuration). After the smaller pipe ends turbulent mixing takes place. Residence times between the T-parts are $12 \mathrm{~ms}$ and $24 \mathrm{~ms}$ for $20 \mathrm{lpm}$ and $40 \mathrm{lpm}$ mixing flows, respectively. 


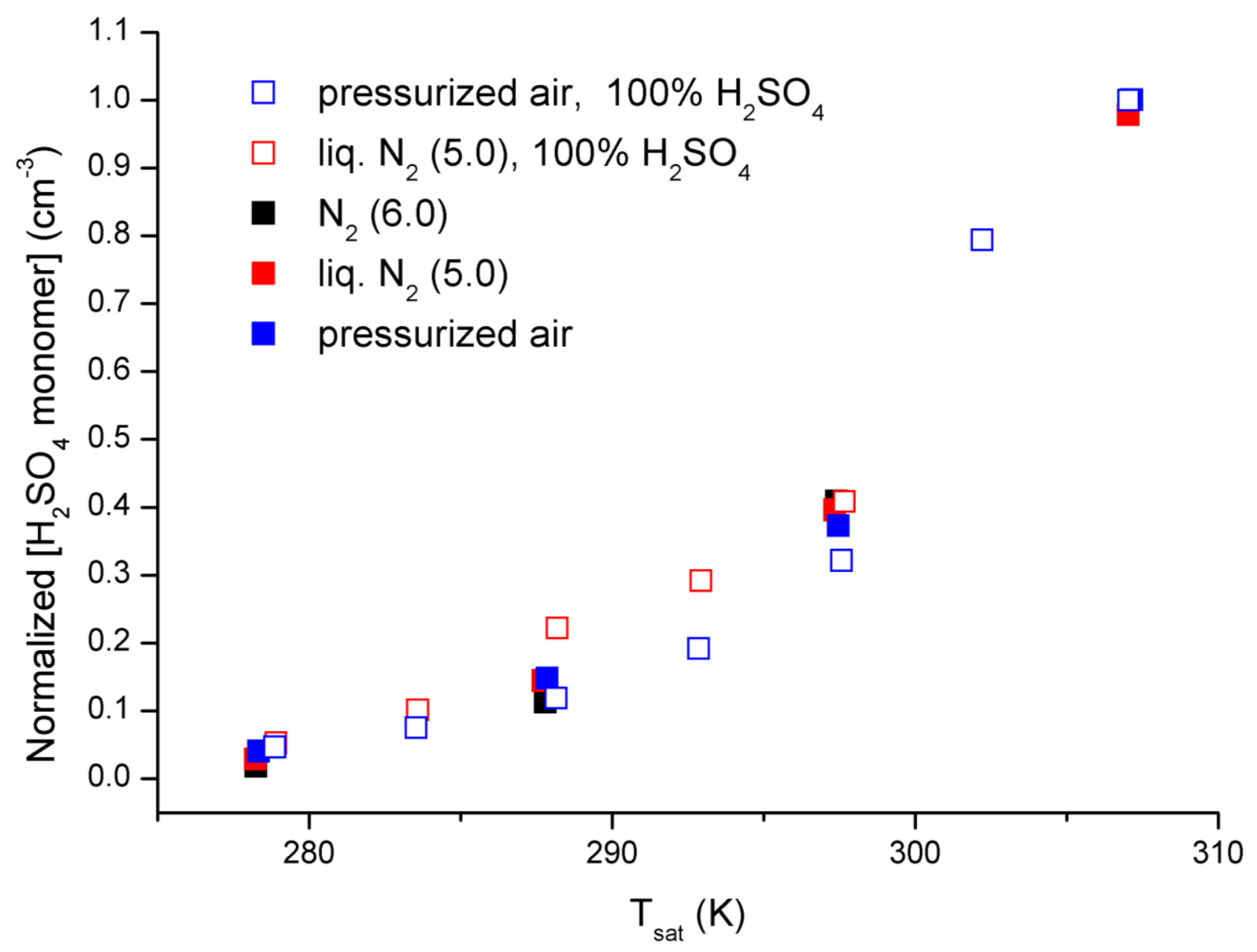

Figure S3. Normalized, averaged $\mathrm{H}_{2} \mathrm{SO}_{4}$ monomer concentration as a function of saturator temperature $T_{\text {sat }}$ for three different carrier gases (pressurized air, $\mathrm{N}_{2}, 5.0$ and 6.0) and two sulphuric acid purity (100\% and $97 \%$ wt.). Saturator flow rate was $0.5 \mathrm{lpm}$. Values are normalized to the maximum value of each mixing flow rate to make different experiments comparable. 


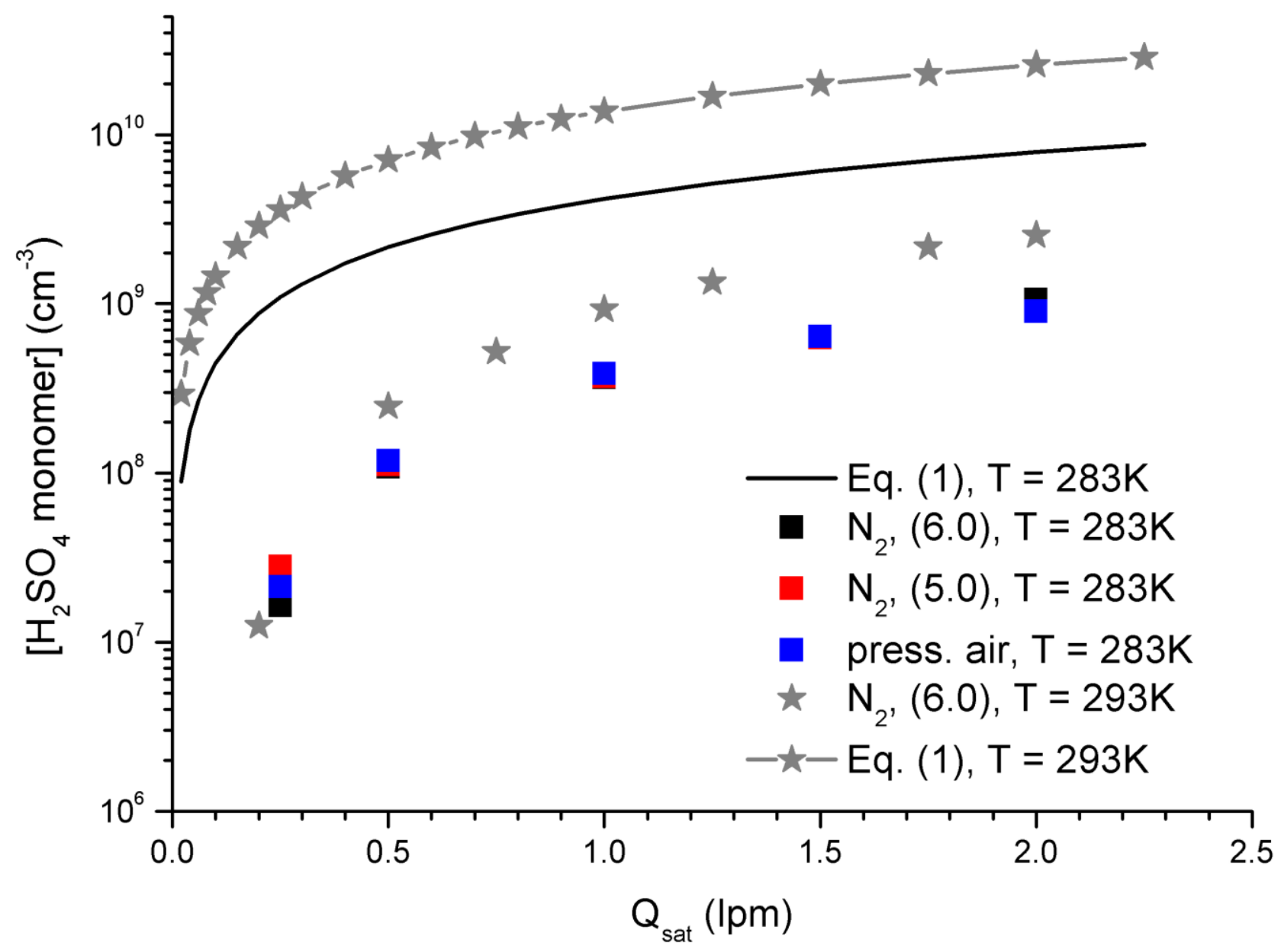

Figure S4. CI-Api-TOF measured $\mathrm{H}_{2} \mathrm{SO}_{4}$ monomer concentration as a function of saturator flow rate $Q_{\text {sat }}$ compared to the predicted value from Eq. (1) for different carrier gases (pressurized air, $\mathrm{N}_{2} 5.0$ and 6.0) at two saturator temperatures (283 K and $293 \mathrm{~K}$ ). Only nitrogen (6.0) was used for saturator temperature of $293 \mathrm{~K}$. 


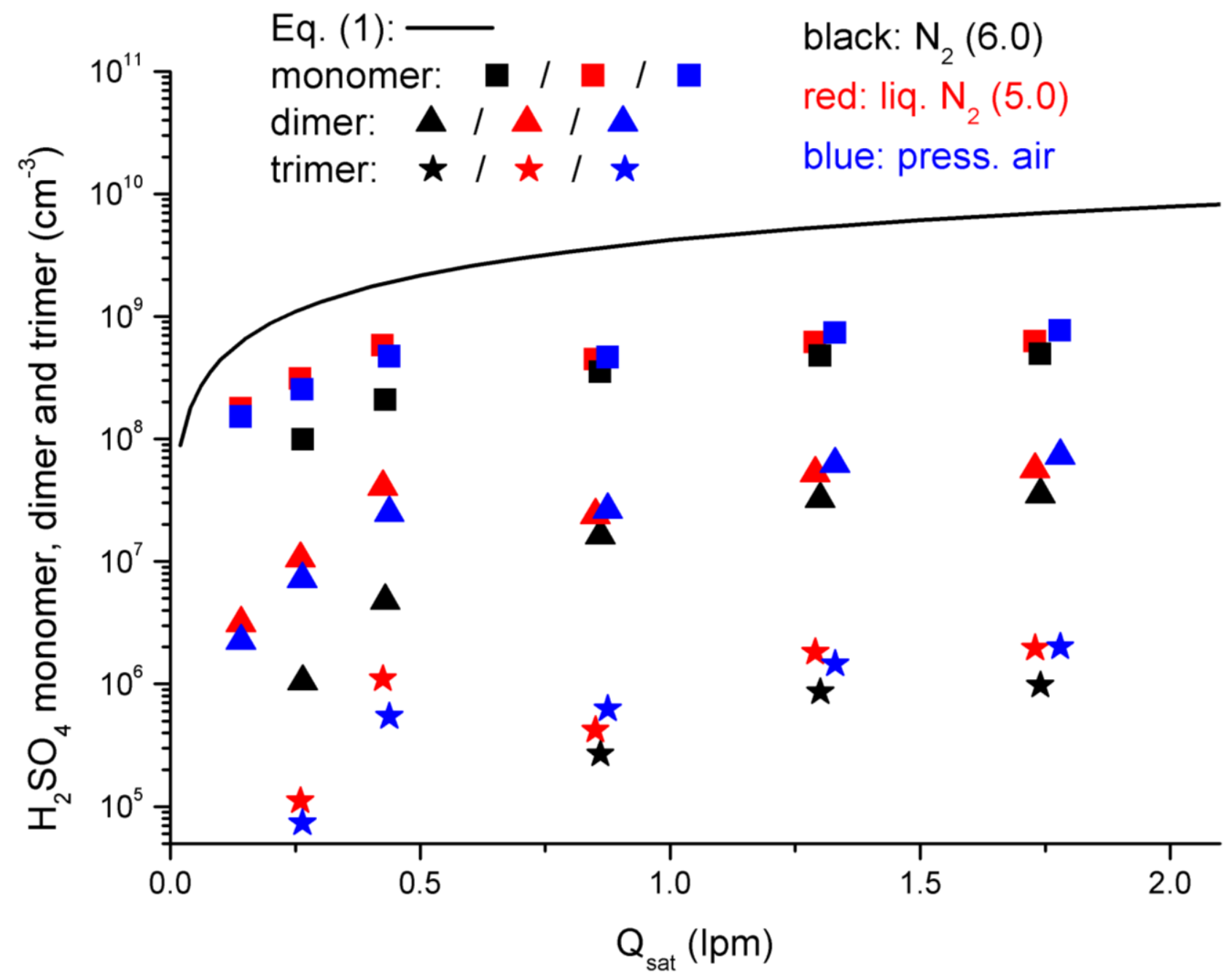

Figure S5. CI-Api-TOF measured $\mathrm{H}_{2} \mathrm{SO}_{4}$ monomer, dimer and trimer concentrations as a function of saturator flow rate $Q_{\text {sat }}$ with three different carrier gases compared to the prediction from Eq. (1) at saturator temperature of $288 \mathrm{~K}$. The first-two points measured using $\mathrm{N}_{2}$ (6.0) are lower than expected due to cleaned measurement lines, where the walls were not yet saturated. The y-axis is limited to $5 \cdot 10^{4} \mathrm{~cm}^{-3}$ which is considered to be the lower detection limit of the CI-Api-TOF. 
a) Pressurized air, $\mathrm{T}=278 \mathrm{~K}$

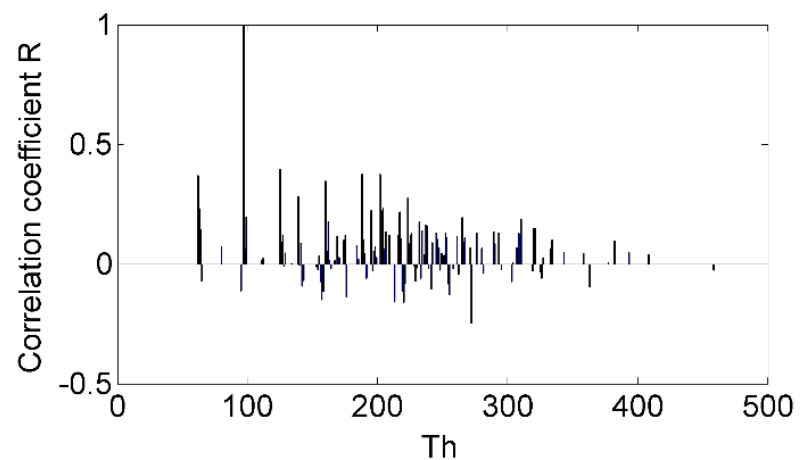

c) Pressurized air, $\mathrm{T}=298 \mathrm{~K}$

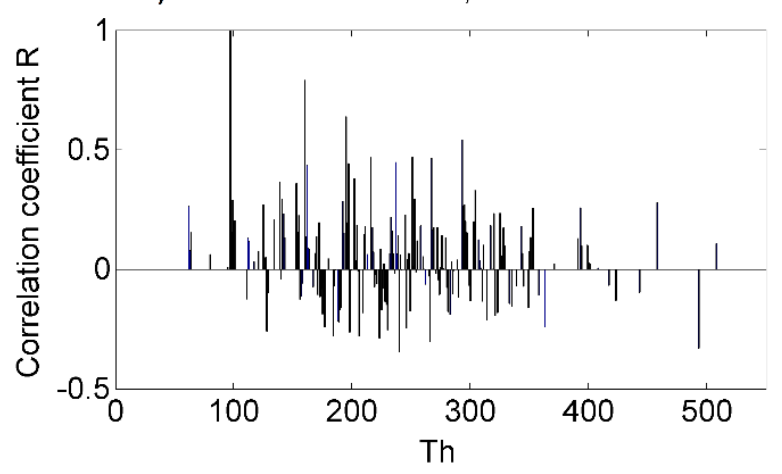

b) Pressurized air, $T=288 \mathrm{~K}$

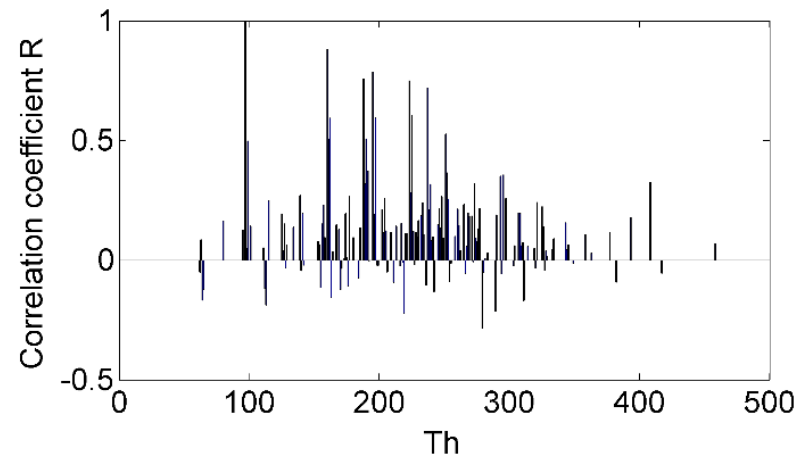

d) Pressurized air, $\mathrm{T}=308 \mathrm{~K}$

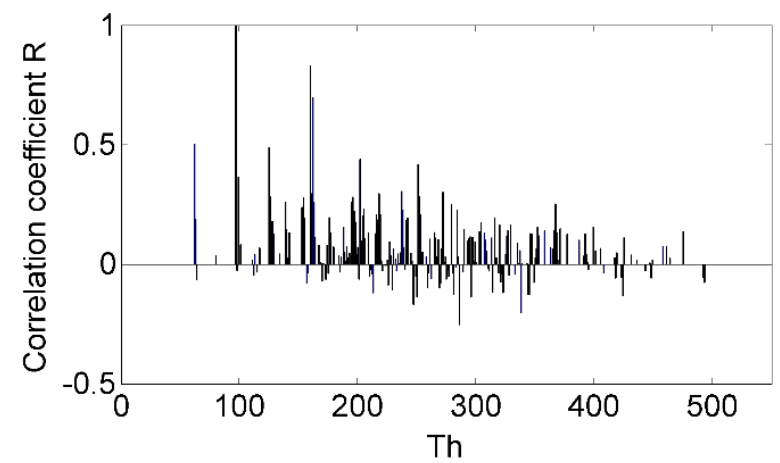

Figure S6. Correlation coefficient of stick masses below $500 \mathrm{Th}$ to $97 \mathrm{Th}\left(\mathrm{HSO}_{4}{ }^{-}\right)$at four different saturator temperatures $(278 \mathrm{~K}, 288 \mathrm{~K}, 298 \mathrm{~K}$ and $308 \mathrm{~K})$ with pressurized air as a carrier gas.

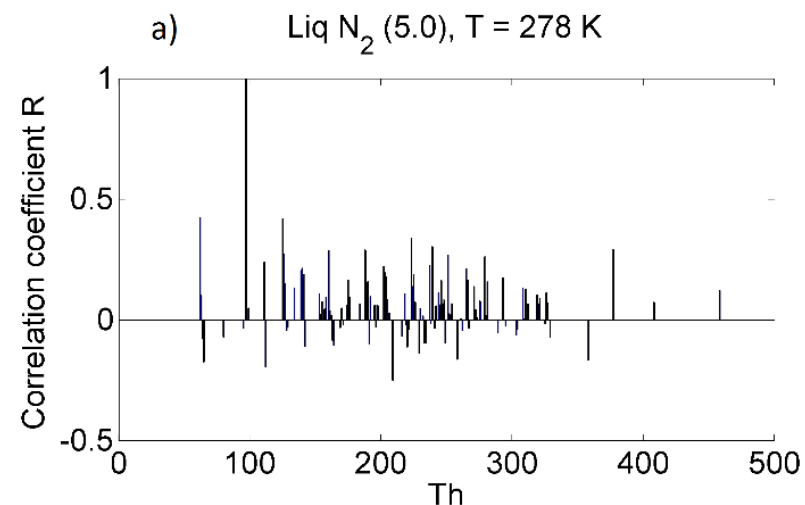

c) $\quad$ Liq $\mathrm{N}_{2}(5.0), \mathrm{T}=298 \mathrm{~K}$

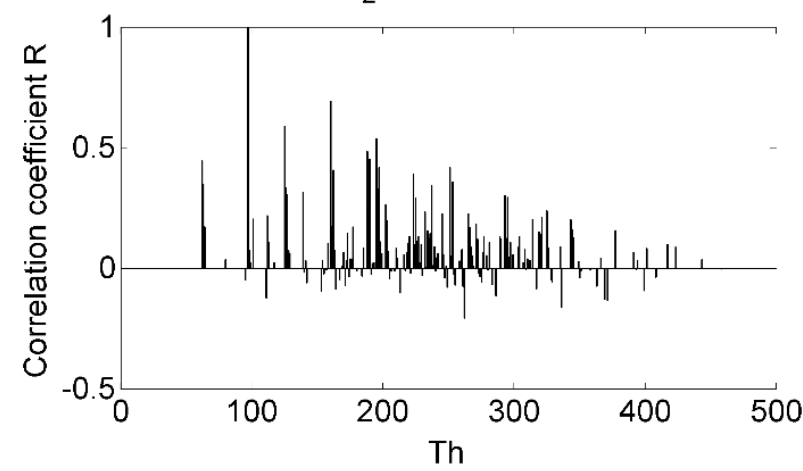

b) $\quad$ Liq $N_{2}(5.0), T=288 \mathrm{~K}$

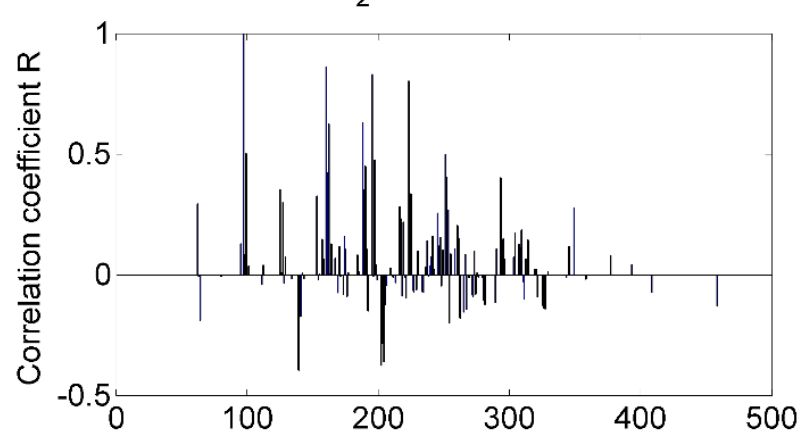

d) $\quad$ Liq $\mathrm{N}_{2}(5.0), \mathrm{Th}=308 \mathrm{~K}$

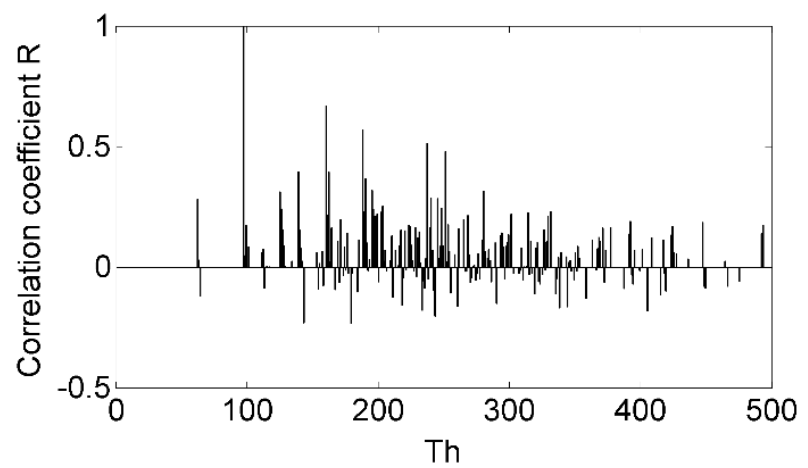

Figure S7. Correlation coefficient of stick masses below 500 Th to $97 \mathrm{Th}\left(\mathrm{HSO}_{4}{ }^{-}\right)$at four different saturator temperatures $(278 \mathrm{~K}, 288 \mathrm{~K}, 298 \mathrm{~K}$ and $308 \mathrm{~K})$ with $\mathrm{N}_{2}(5.0)$ from liquid source as a carrier gas. 

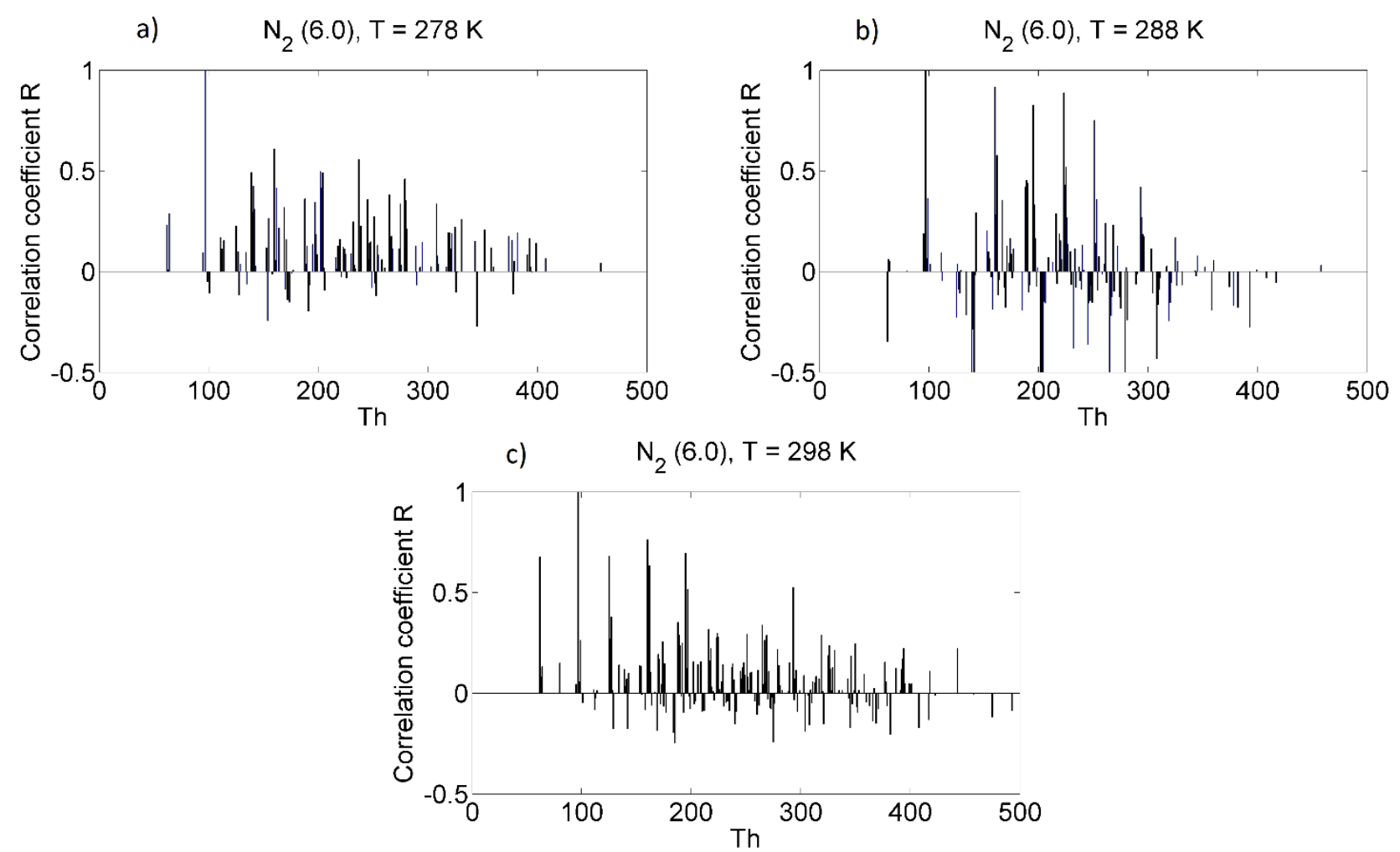

Figure S8. Correlation coefficient of stick masses below 500 Th to $97 \mathrm{Th}\left(\mathrm{HSO}_{4}{ }^{-}\right)$at three different saturator temperatures $(278 \mathrm{~K}, 288 \mathrm{~K}$ and $298 \mathrm{~K})$ with $\mathrm{N}_{2}(6.0)$ as a carrier gas.

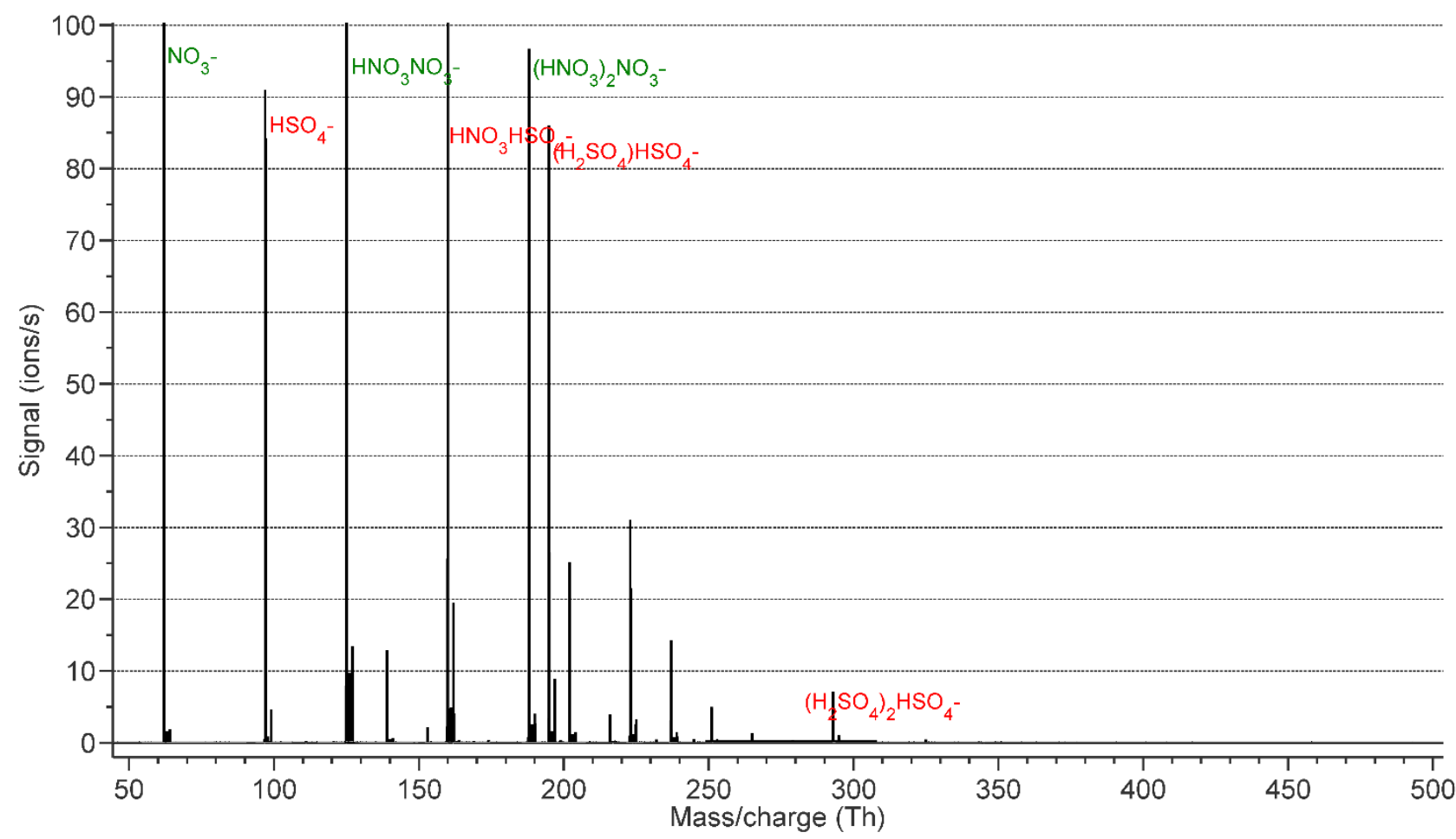

Figure S9. One-hour-average mass spectra from CI-Api-TOF from 25 to 500 Th with $\mathrm{N}_{2}(6.0)$ as carrier gas at saturator temperature of $298 \mathrm{~K}$. The peaks used for calculation of monomer, dimer and trimer concentrations are marked in the figure. 


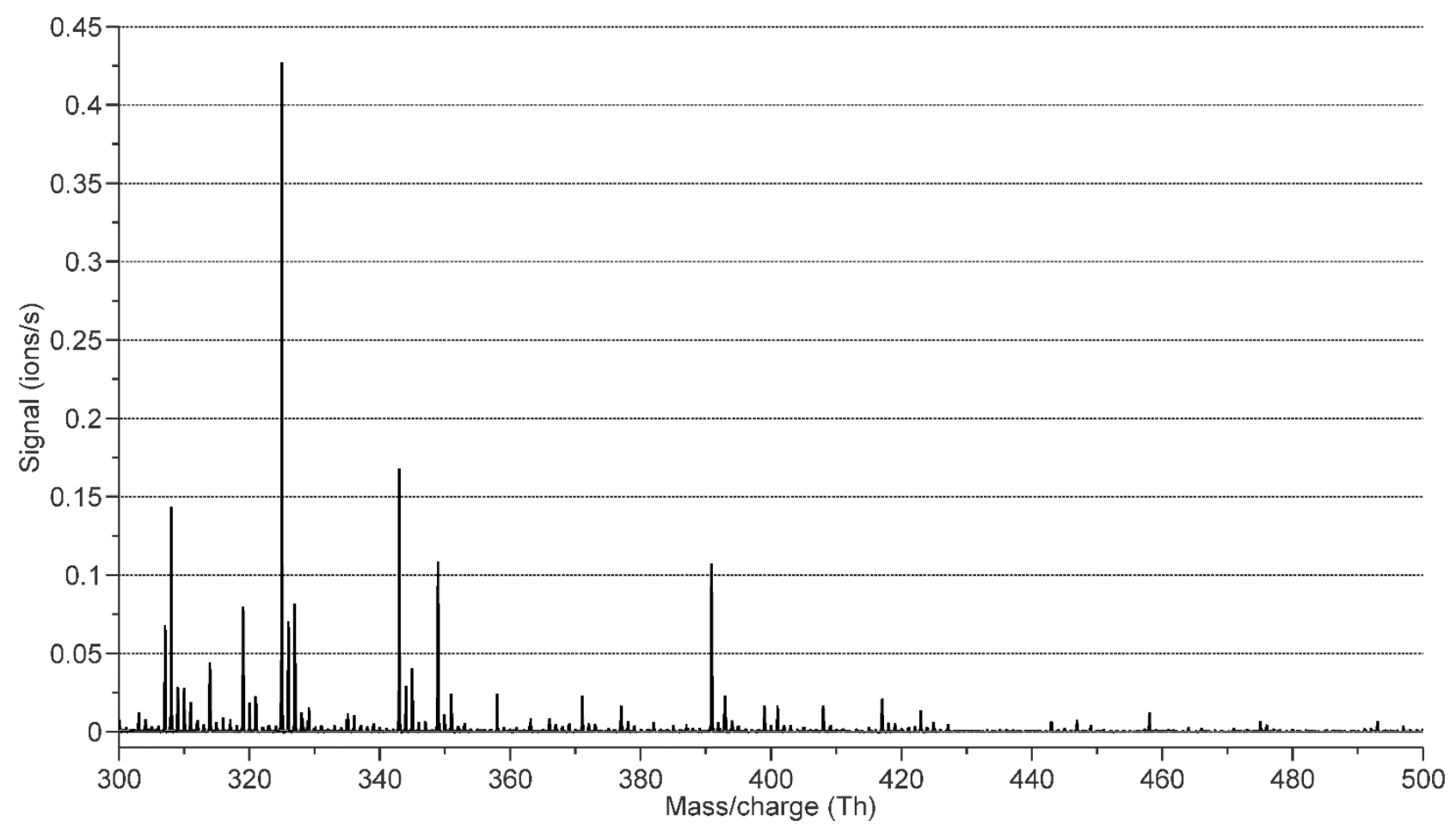

Figure S10. One-hour-average mass spectra from CI-Api-TOF from 300 to 500 Th with $\mathrm{N}_{2}(6.0)$ as carrier gas at saturator temperature of 298 K. Zoomed from Figure S9.

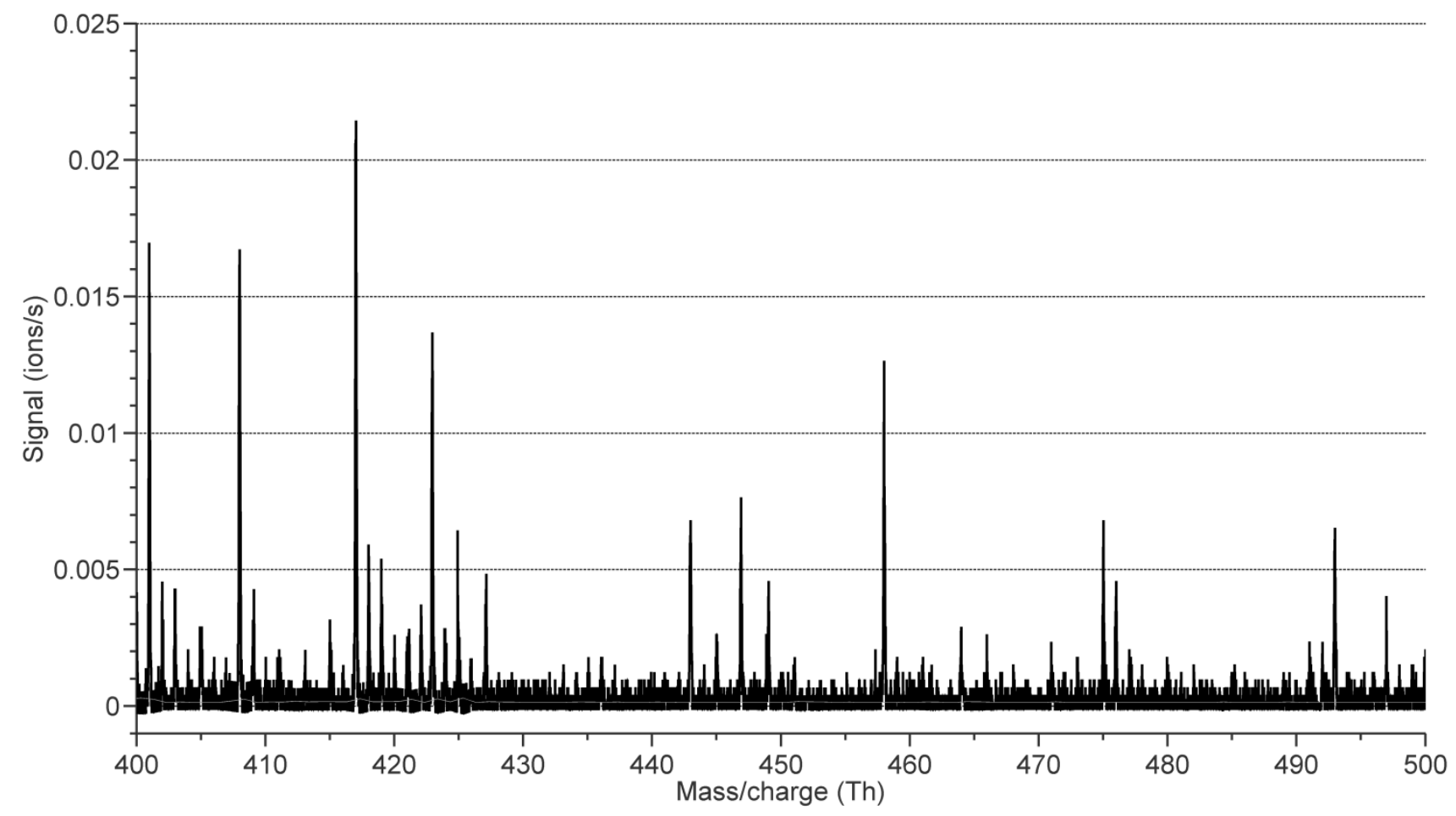

Figure S11. One-hour-average mass spectra from CI-Api-TOF from 400 to 500 Th with $\mathrm{N}_{2}(6.0)$ as carrier gas at saturator temperature of 298 K. Zoomed from Figure S9. 

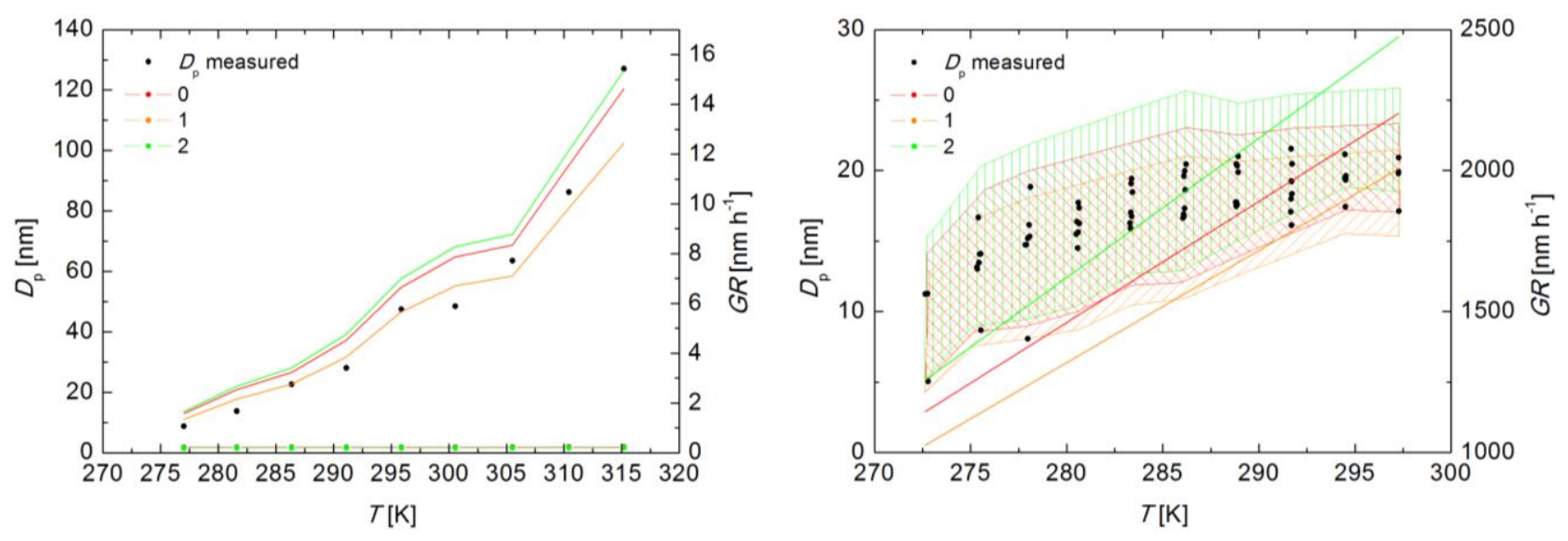

Figure S12. Modelled particle diameters $D_{p}$ and growth rates $G R$ as a function of the saturator temperature $T_{\text {sat }}$ using $1.5 \mathrm{~nm}$ as an initial cluster size and initial sulphuric-acid monomer (left panel) or initial total-sulphate concentration (right panel) as an input for the model. Solid lines are growth rates, lines with symbols (left panel) or shaded area (right panel) are the modelled diameters and black dots are measured geometric mean diameters. Three different ammonia uptake scenarios is used: (0) no uptake of ammonia, (1) uptake of ammonia with the same rate as sulphuric acid and (2) double uptake rate for ammonia, compared to sulphuric acid. Shaded area on the panel on the right is between the minimum and the maximum modelled particle diameter, using minimum and maximum measured total-sulphate concentration on the same saturator temperature. 